\title{
RESEARCH
}

Open Access

\section{The impact of family planning on maternal mortality in Indonesia: what future contribution can be expected?}

\author{
Budi Utomo ${ }^{1 *} \mathbb{D}$, Purwa Kurnia Sucahya ${ }^{2}$, Nohan Arum Romadlona', Annette Sachs Robertson ${ }^{3}$, \\ Riznawaty Imma Aryanty ${ }^{4}$ and Robert Joseph Magnani ${ }^{5}$
}

\begin{abstract}
Background: Although efforts to reduce high maternal mortality in countries such as Indonesia tend to focus on addressing health risks among pregnant women, family planning has been shown globally to reduce maternal mortality by reducing both total and higher-risk pregnancies. This article assesses past contributions of family planning to the reduction of maternal mortality in Indonesia and the potential future contribution toward achieving the 2030 SDG maternal mortality goal.
\end{abstract}

Methods: The study takes advantage of data from long series of population censuses and large-scale surveys that are available in few other low- and middle-income countries. We use the decomposition method suggested by (Matern Child Health J, 16:456-463, 2012) and regression-based policy simulations to estimate the number of maternal deaths averted during 1970-2017 due to contraceptive use and project potential future contributions to the year 2030.

Results: It is estimated that between 523,885 and 663,146 maternal deaths were averted from 1970 to 2017 due to contraceptive use, a 37.5-43.1\% reduction. If the contraceptive prevalence rate (CPR) were to rise from 63\% in 2017 to $70 \%$ in 2030 and unmet need for family planning were to fall to from 10 to $7 \%$, an additional $34,621-37,186$ maternal deaths would be averted, an 18.9-20.0\% reduction. A 2030 CPR of $75 \%$ and unmet need for family planning of 5\% would result in 51,971-54,536 maternal deaths being averted, a 28.4-29.4\% reduction. However, the CPR growth rate would have to nearly double the 2000-2017 rate to reach 70\% CPR by 2030 and more than triple to reach $75 \%$. Achieving the most ambitious target would still leave the maternal mortality ratio at 125 in 2030 without corresponding improvements in maternal health services.

Conclusions: Although substantial reductions in maternal mortality between 1970 and 2017 can be attributed to contraceptive use and further contributions to the year 2030 are probable, smaller contributions are likely due to the already relatively high CPR and the challenges that must be overcome to move the CPR significantly higher. The ability of Indonesia to reach the 2030 SDG maternal mortality target of 70 maternal deaths per 100,000 live births will depend primarily upon health system effectiveness in addressing health risks to women once they are pregnant.

Keywords: Family planning, Maternal mortality, Indonesia

\footnotetext{
* Correspondence: budi.utomo.ui@gmail.com

'Department of Population and Biostatistics, Faculty of Public Health, Universitas Indonesia, Depok, Indonesia

Full list of author information is available at the end of the article
}

(c) The Author(s). 2021 Open Access This article is licensed under a Creative Commons Attribution 4.0 International License, which permits use, sharing, adaptation, distribution and reproduction in any medium or format, as long as you give appropriate credit to the original author(s) and the source, provide a link to the Creative Commons licence, and indicate if changes were made. The images or other third party material in this article are included in the article's Creative Commons licence, unless indicated otherwise in a credit line to the material. If material is not included in the article's Creative Commons licence and your intended use is not permitted by statutory regulation or exceeds the permitted use, you will need to obtain permission directly from the copyright holder. To view a copy of this licence, visit http://creativecommons.org/licenses/by/4.0/ The Creative Commons Public Domain Dedication waiver (http://creativecommons.org/publicdomain/zero/1.0/) applies to the data made available in this article, unless otherwise stated in a credit line to the data. 


\section{Introduction}

Globally, both the number of maternal deaths and the rate at which maternal deaths occur have declined dramatically since 1990 [3, 29]. Despite adopting comprehensive safe-motherhood policy measures, maternal mortality in Indonesia remains unacceptably high. Various methods of estimating maternal mortality in Indonesia during the past decade have consistently produced maternal mortality ratios (MMR) between 200 and 350 maternal deaths per 100,000 live births [10, 17]. The current official Government of Indonesia estimate of the maternal mortality ratio based on the 2015 InterCensal Population Survey (SUPAS) is 305 maternal deaths per 100,000 live births [19]. The global Maternal Mortality Estimation Inter-Agency Group, using a different methodology than the Government of Indonesia, put the MMR at 126 per 100,000 live births in 2015 [29]. Irrespective of which estimate is used, the Indonesian MMR is high. By way of comparison, the estimated MMRs in 2017 in Association of Southeast Asian Nations (ASEAN) comparator nations were Thailand (20), Brunei (23), Malaysia (40), Vietnam (54), and Philippines (114) [30]. Most maternal deaths are preventable, as the health care solutions to prevent or manage complications are well known [29].

A global consensus has emerged as to core strategies to reducing maternal mortality. These consist of (1) family planning with related reproductive health services, (2) skilled care during pregnancy and childbirth, (3) timely emergency obstetric care, and (4) immediate postnatal care [28]. In contrast with the other three interventions, which focus on reducing risk among women who are or recently were pregnant, family planning programs reduce maternal mortality by (1) reducing the number of pregnancies that occur and (2) reducing the proportion of pregnancies that are deemed to be "higher-risk" [16]. Fewer pregnancies translate into a reduction in the number of times that women are exposed to the risk of maternity-related mortality, an impact that compounds over time as fewer births yields successive generations of smaller cohorts of women of reproductive age. Contraceptive use is a key direct determinant of fertility reduction $[5,9,23]$, the other "proximate determinants" being marriage/sexual exposure, postpartum infecundability, and induced abortion [6]. Contraceptive use also lowers the risk of maternal mortality per birth, as measured by the MMR, by preventing high-risk births, that is, births to women who are "too young" or "too old," birth intervals that are "too close," and high-parity births (i.e., "too many") [8, 23]. Family planning has been estimated to have reduced maternal mortality levels in various countries by magnitudes ranging from 6 to $60 \%[1,7]-44 \%$ globally [16], as well as lowering infant mortality and abortion rates, especially unsafe abortions [13, 26].
Mbizvo and Burke [14] estimate that globally family planning could prevent up to $30 \%$ of maternal deaths going forward.

Indonesia has been among the global leaders in family planning. The success of the national family planning program is evidenced by the sharp increase in the contraceptive prevalence rate (CPR) among married women from $8 \%$ in the early 1970 s to $60 \%$ in 2002 , while during the same time period the total fertility rate (TFR) was reduced by nearly one-half from 5.0 to $2.6[18,22]$. Although the rate of growth in contraceptive use has slowed since the early of 2000 s, CPR reached $63 \%$ in 2017 and the TFR fell to 2.3 [20].

As the Government of Indonesia struggles to reduce stubbornly high rates of maternal mortality, the research reported in this article sought to provide a clearer understanding as to the impact that contraceptive use had had on maternal mortality in the country over a 35year period and the likely magnitude of future contributions. Having scientifically sound assessments of future contributions is important for national policy and resource allocation decisions given the already relatively high level of contraceptive use and the diminishing rate of growth in contraceptive prevalence over the past two decades. We took advantage of long series of population census, large-scale surveys, and other data that are available in Indonesia but in few other low-and-middle-income countries to pursue these research objectives.

\section{Materials and methods}

The basic methodologies used in the study consisted of a modified version of the decomposition method suggested by Ross and Blanc [16] along with policy simulations. Ross and Blanc show that the number of maternal deaths in any given year can be decomposed into three statistical components: the number of women of reproductive age (WRA), the general fertility rate (GFR), and the maternal mortality ratio (MMR) (see Fig. 1). That is:

$$
\mathrm{MD}=\mathrm{WRA} * \mathrm{GFR} * \mathrm{MMR}
$$

where:

$\mathrm{MD}=$ number of maternal deaths during a specified year WRA = number of women at reproductive age at midpoint of a specified year

GFR = general fertility rate, defined as number of births during a specified year divided by number of WRA at the mid-point of a specified year

MMR = maternal mortality ratio in the specified year, defined as number of maternal deaths divided by number of live births during the same year

Data on WRA, GFR, and MMR for the years 1970 to 2017 needed for the maternal death decomposition analysis were gathered from multiple data sources (see 
Annex 1 for a full listing of data sources). Population data by age and gender were extracted from Population Censuses (1971, 1980, 1990, 2000, and 2010) and InterCensal Population Surveys (1985, 1995, 2005, and 2015). Annual, smoothed values during the 1970-2017 period were obtained using least-squares polynomial regressions. A similar process was followed in deriving annual figures of GFR and MMR, with fertility and maternal mortality data coming from a variety of surveys and other sources (see Annex 1).

To quantify the contributions of contraceptive use to declining maternal mortality, we ran a series of policy simulations in which we compared the results of the basic decomposition results against selected "counterfactual" scenarios. To estimate the impact of contraception on maternal mortality during the 1970-2017 period, the "baseline" decomposition results were compared against a counterfactual projection assuming no change in the contraceptive prevalence rate (CPR) between 1970 and 2017. The potential future impact of contraceptive use on maternal mortality was then estimated by comparing alternative scenarios with regard to the magnitude of CPR growth from 2017 to 2030. The first scenario assessed the impact of an increase in the contraceptive prevalence rate (CPR) from $63 \%$ in 2017 to $70 \%$ in the year 2030 and a decline in unmet need for family planning from $10 \%$ in 2017 to $7 \%$ in 2030. In the second scenario, CPR was assumed to increase from $63 \%$ in 2017 to $75 \%$ in 2030 and unmet need for family planning to decline from $10 \%$ in 2017 to $5 \%$ in 2030 . The WRA figures used in the analyses were derived from Statistics Indonesia population projections to the year 2030 [18, 22]. Annual GFR and MMR values for the projections for the alternative scenarios were estimated using a regression approach, the details of which are documented along with the presentation of results.
In undertaking the analyses, we made two refinements to the basic decomposition method of Ross and Blanc [16]. One limitation of this decomposition approach, which was recognized by the authors, is that changes in GFR are not only the result of changes in contraceptive use but also of changes in other "proximate determinants" of fertility, the most prominent of which are marriage, postpartum infecundability, and abortion $[4,6]$. To address this issue, we examined trends in the main non-contraception proximate determinants of fertility over the 1970-2017 period and, based upon these data and the published literature on this topic, derived an estimate of the percentage of the change in GFR that was attributable to contraceptive use. We undertook sensitivity analyses to assess the implications of uncertainty regarding this parameter on subsequent results. Further details are provided along with the presentation of results.

Second, as the global literature is clear that family planning affects the MMR by reducing the number of high-risk pregnancies/births as well as by reducing the number of women becoming pregnant, the observed MMR data will include these high-risk pregnancy/birth effects and it is thus necessary to account for this effect in order to correctly quantify the impact of contraceptive use in the policy simulations. To address this issue, we examined changes in agespecific fertility rates, parity, and lengths of closed birth intervals from 1970 to 2017, and as above based upon these data and the published literature, we derived an estimate of what the observed MMRs would have been in the absence of declines in the CPR. A sensitivity analyses was also undertaken for this subanalysis to assess the implications of uncertainty on subsequent results. Further details are provided along with the presentation of study findings.

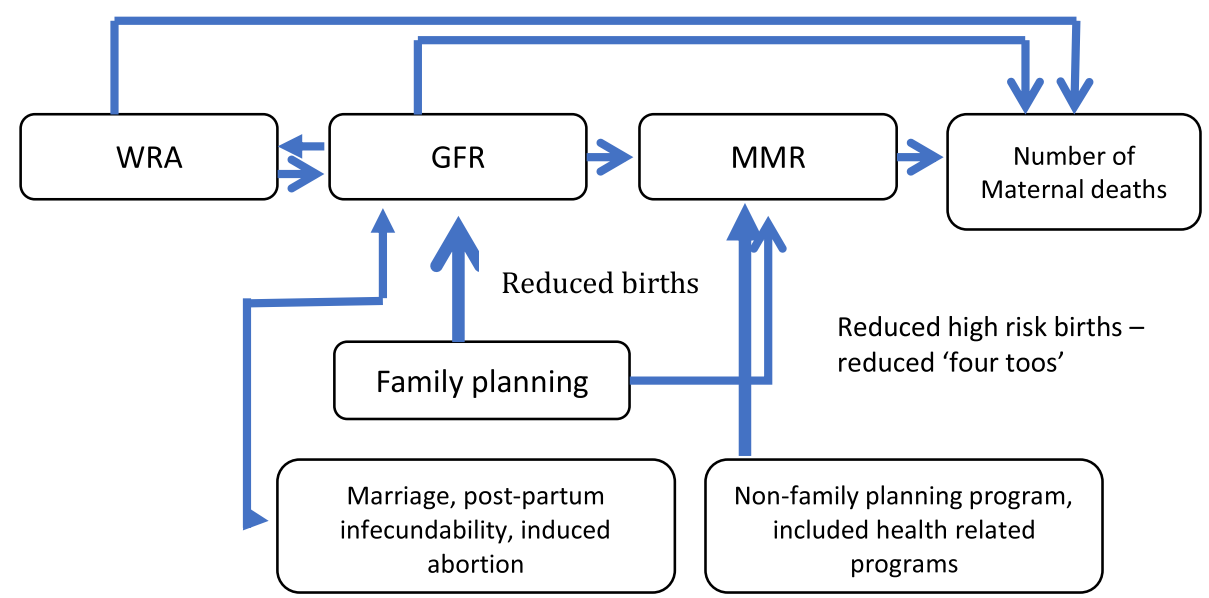

Fig. 1 Analytic framework — how family planning reduces maternal deaths 


\section{Results}

\section{Baseline decomposition results}

The annual estimates of the maternal death decomposition components (WRA, GFR, and MMR) developed for the period of 1970-2017 are displayed in condensed form for selected years in Table 1. Despite the number of WRA having almost tripled during this reference period, the annual number of births varied within a relatively narrow range (4.6 to 5.2 million) due to a $64 \%$ reduction in the GFR. The analysis used the best-fitting quadratic regression $y=0.0697 x^{2}-$ $9.5793 x+553.86(\mathrm{R}$ square $=0.6656)$ to smooth the trend of reported MMR estimates during the period. Based upon these procedures, it is estimated that the MMR fell from 544 in 1970 to under 300 by 2005 and has since been declining at a slower pace. This resulted in a $43.7 \%$ reduction in the annual number of maternal deaths from just over 25,000 in the early 1970 s to just over 13,000 in 2017 . The maternal mortality rate, which is a measure of the risk of maternal deaths per 1000 WRA, fell by $82 \%$ during this same period. The trends in WRA, GFR, and MMR are shown visually in Fig. 2.

\section{Contraception and other proximate determinants of fertility decline}

To what extent can the decline in the GFR be attributed to increases in contraceptive use? As shown in Fig. 3, since the start of the national family planning program in the early of 1970s, the CPR increased sharply to over $40 \%$ in the early 1990 s and to $63 \%$ in 2017, while TFR declined sharply from just under 6 in the early 1970 s to 2.3 in 2017, although the rates of decline have slowed considerably since the early 2000s. Unmet need for family planning (UNFP) declined from $17.0 \%$ in 1991 to $10.6 \%$ in 2017.
Trends in the major proximate determinants of fertility other than contraception are shown in Table 2 . With regard to marriage, singulate mean age at first marriage increased rather substantially from 19.1 years in 1987 to 22.4 years in 2017, while the proportion of women ages 45 and above who never married also increased slightly. These trends would both have had a dampening effect on fertility. The median duration of exclusive breastfeeding increased since 1995, while the median duration of any breastfeeding declined by a comparable amount. Given that the median length of exclusive breastfeeding in Indonesia remains relatively short, these trends are unlikely to have had a major influence on fertility trends over the past 20 or so years. We were precluded from including abortion in the analysis due to a lack of reliable data.

Earlier data from low- and middle-income countries indicated that differences in contraceptive prevalence explained about $90 \%$ of the variation in fertility rates across countries [15]. Based on the available Indonesian data and global evidence, we conservatively assumed that contraceptive use was responsible for $80 \%$ of reduced fertility during the 1970-2017 period in the policy simulations. However, especially given the lack of information on abortion levels or trends, we undertook sensitivity analyses in the policy simulations in which we assessed the consequences of this parameter being either too high or too low-specifically, $85 \%$ and $75 \%$.

\section{Contribution of family planning to reducing high-risk births}

To assess family planning contributions to reducing highrisk births, we examined trends in factors that have been linked with high-risk births in the literature. These factors included unwanted births and births from pregnancies that were "too young, too old, too many or too close." Although it is difficult to isolate the specific effects of wanted status

Table 1 Maternal death decomposition results, Indonesia 1970-2017

\begin{tabular}{|c|c|c|c|c|c|c|}
\hline Years & WRA & GFR & Births & Maternal mortality ratio & Maternal deaths & Maternal mortality rate \\
\hline 1970 & $26,042,390$ & 177 & $4,617,379$ & 544 & 25,135 & 0.97 \\
\hline 1975 & $31,200,951$ & 159 & $4,966,205$ & 499 & 24,776 & 0.79 \\
\hline 1980 & $36,270,530$ & 140 & $5,075,444$ & 457 & 23,191 & 0.64 \\
\hline 1985 & $41,251.126$ & 122 & $5,026,855$ & 418 & 21,034 & 0.51 \\
\hline 1990 & $46,142,740$ & 106 & $4,894,523$ & 383 & 18,767 & 0.41 \\
\hline 1995 & $50,945,371$ & 93 & $4,744,862$ & 352 & 16,698 & 0.33 \\
\hline 2000 & $55,659,020$ & 83 & $4,636,614$ & 324 & 15,017 & 0.27 \\
\hline 2005 & $60,283,686$ & 77 & $4,620,847$ & 299 & 13,832 & 0.23 \\
\hline 2010 & $64,819,370$ & 73 & $4,740,958$ & 278 & 13,193 & 0.20 \\
\hline 2015 & $69,266,071$ & 73 & $5,032,670$ & 261 & 13,120 & 0.19 \\
\hline 2017 & $71,019,837$ & 73 & $5,203,944$ & 255 & 13,251 & 0.19 \\
\hline
\end{tabular}




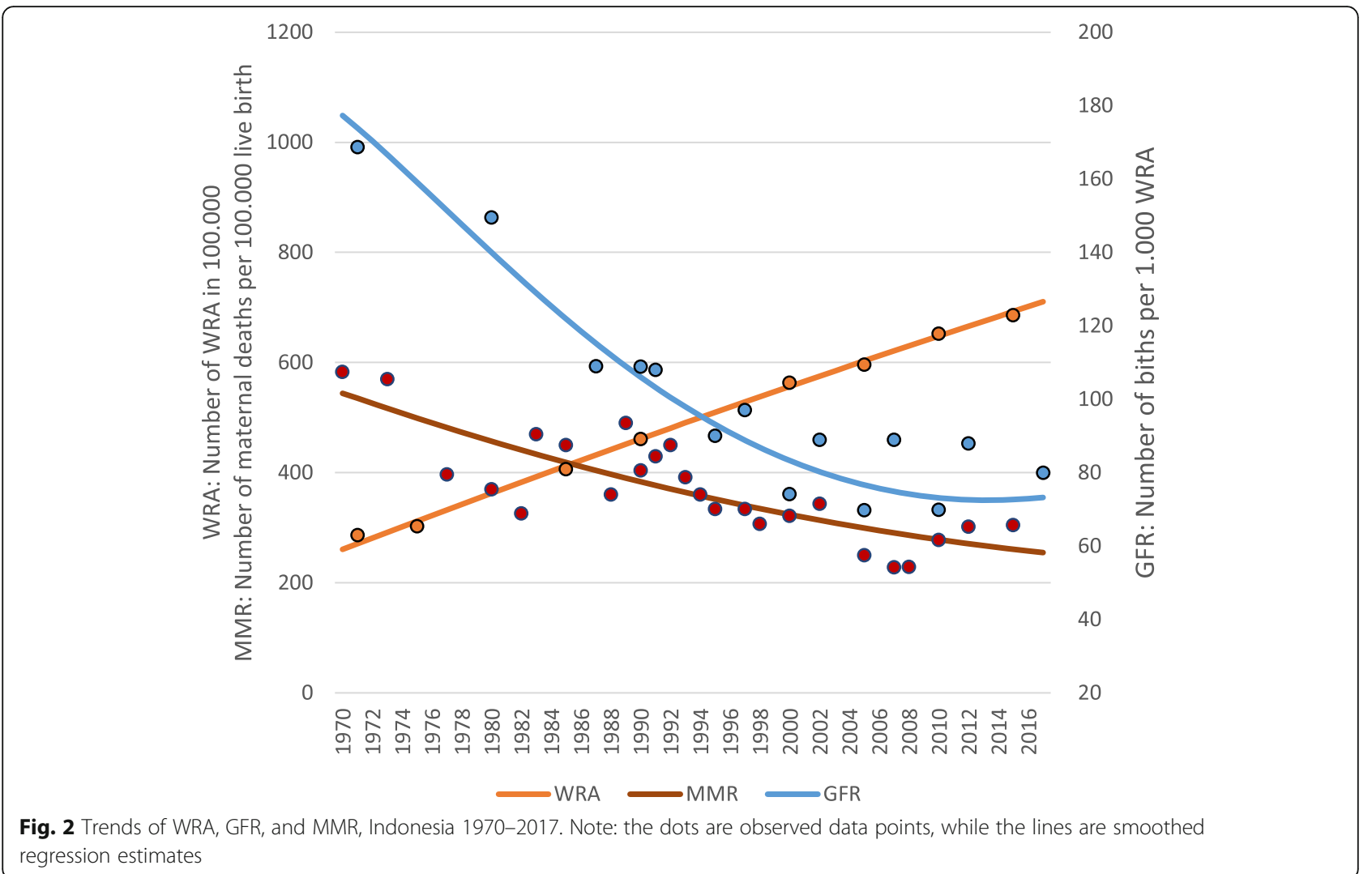

on maternal mortality from the effects of other factors because a significant number of unwanted pregnancies occur to women who are at also risk for other reasons (e.g., age, parity, time since last birth), the literature suggests a strong link between unwanted status and abortion, which is clearly associated with maternal mortality risk [23, 26]. An analysis of the planning status of recent births from the series of seven (7) DHS surveys undertaken in Indonesia indicates an increase in proportion of recent births that were "wanted then" from $77.4 \%$ in 1987 to $84.0 \%$ in 2017.

More substantial changes over time are observed with regard to age, parity, and birth interval risks (Table 3).

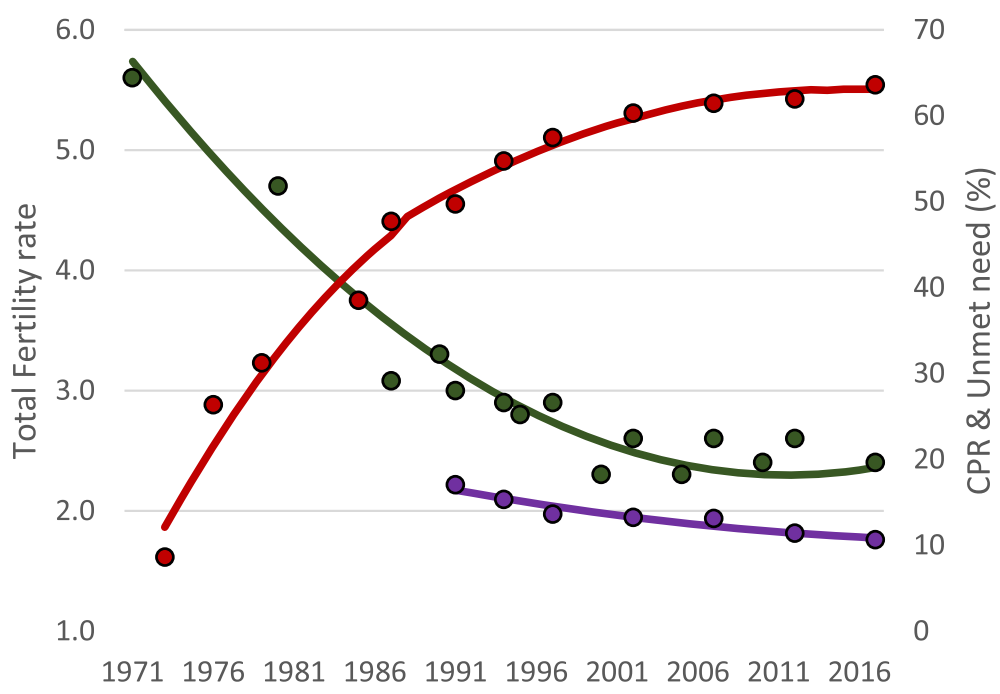


Table 2 Trends in proximate determinants of fertility other than contraception, 1970-2017

\begin{tabular}{lllll}
\hline Year & $\begin{array}{l}\text { Singulate mean age at } \\
\text { first marriage }\end{array}$ & $\begin{array}{l}\text { \% never } \\
\text { married }\end{array}$ & $\begin{array}{l}\text { Median duration of exclusive } \\
\text { breastfeeding }\end{array}$ & $\begin{array}{l}\text { Median duration of any } \\
\text { breastfeeding }\end{array}$ \\
\hline $\mathbf{1 9 7 0}$ & 19.1 & 1.5 & na & na \\
$\mathbf{1 9 7 5}$ & 19.5 & 1.9 & na & na \\
$\mathbf{1 9 8 0}$ & 20.3 & 2.2 & na & na \\
$\mathbf{1 9 8 5}$ & 20.9 & 2.5 & na & na \\
$\mathbf{1 9 9 0}$ & 21.5 & 2.7 & na & 23.0 \\
$\mathbf{1 9 9 5}$ & 21.9 & 2.8 & 1.8 & 22.4 \\
$\mathbf{2 0 0 0}$ & 22.2 & 2.9 & 1.5 & 21.9 \\
$\mathbf{2 0 0 5}$ & 22.3 & 2.9 & 1.0 & 21.6 \\
$\mathbf{2 0 1 0}$ & 22.3 & 2.9 & 1.1 & 21.4 \\
$\mathbf{2 0 1 5}$ & 22.3 & 2.7 & 2.6 & \\
$\mathbf{2 0 1 7}$ & 22.4 & 2.7 & 3.7 & 21.3 \\
\hline
\end{tabular}

With regard to age risk, the percent declines in agespecific fertility rates among young (ages 15-19years) and older women (ages 40-49 years) between 1970 and 2017 exceeded that for women in the "safe" ages, and by a considerable margin. The proportion of births resulting from pregnancies that were "too many" and/or "too close" have also declined significantly. The proportion of last births that were parity four or above declined from $35 \%$ in 1987 to $12 \%$ in 2017 , while the median of length of the interval between the last two births lengthened from 38 months in 1991 to 65 months in 2017. Based on the literature and the available Indonesian data, we used an estimate of $15 \%$ contribution of contraceptive use to the reduction of the MMR via reduction in numbers of high-risk births in our policy simulations. Sensitivity analyses were undertaken in connection with the policy simulations in which we assessed the consequences of this parameter instead being $20 \%$ and $10 \%$, respectively.

\section{Family planning and maternal deaths averted}

To assess the impact of contraceptive use on the number of maternal deaths, we compared the baseline decomposition analysis results (see Table 1) against a counterfactual projection that assumed no changes in CPR from 1970 onward. As described above, we simulated the impact of contraception on fertility by reducing the projected decline in annual GFRs in the counterfactual projection by $20 \%$ consistent with the above estimate that contraception accounted for $80 \%$ of changes in fertility and other proximate determinants the remaining $20 \%$. Similarly, we adjusted the projected decline in the maternal mortality ratio (MMR) by $15 \%$ to reflect the estimated contribution to MMR reduction via the reduction in numbers of high-risk births. Tables 4 and 5 present the results of these policy simulations.

Table 4 presents estimates of births averted during the 1970-2017 period and selected sub-periods therein.

Table 3 Age-specific fertility rates and total fertility rates, Indonesia 1970-2017

\begin{tabular}{|c|c|c|c|c|c|c|c|c|}
\hline \multirow[t]{2}{*}{ Year } & \multicolumn{7}{|c|}{ Age group } & \multirow[t]{2}{*}{ TFR } \\
\hline & 15-19 & $20-24$ & $25-29$ & $30-34$ & $35-39$ & $40-44$ & $45-49$ & \\
\hline 1970 & 153 & 291 & 276 & 216 & 124 & 56 & 18 & 5.7 \\
\hline 1975 & 128 & 254 & 242 & 186 & 109 & 48 & 15 & 4.9 \\
\hline 1980 & 106 & 222 & 213 & 161 & 95 & 40 & 12 & 4.3 \\
\hline 1985 & 87 & 194 & 188 & 140 & 84 & 34 & 10 & 3.7 \\
\hline 1990 & 72 & 171 & 167 & 123 & 75 & 29 & 8 & 3.3 \\
\hline 1995 & 59 & 151 & 151 & 110 & 68 & 25 & 6 & 2.9 \\
\hline 2000 & 50 & 136 & 140 & 102 & 63 & 22 & 5 & 2.6 \\
\hline 2005 & 44 & 125 & 133 & 99 & 60 & 20 & 4 & 2.5 \\
\hline 2010 & 41 & 119 & 131 & 100 & 60 & 19 & 4 & 2.5 \\
\hline 2015 & 42 & 117 & 133 & 105 & 61 & 19 & 4 & 2.4 \\
\hline 2017 & 43 & 117 & 135 & 108 & 62 & 20 & 4 & 2.4 \\
\hline \% decline 1970-2017 & 71.9 & 59.8 & 51.1 & 50.0 & 50.0 & 64.3 & 77.8 & \\
\hline
\end{tabular}


Comparing the estimates from the observed, smoothed data (referred to as the "Baseline") and the scenario with no change in CPR after 1970 (scenario 1), it is estimated that the Indonesian national family planning program averted 150.5 million births during 1970-2017, a 40.7\% averted. The majority of births averted, 94.8 million, occurred after the year 2000 when CPR had already surpassed $50 \%$.

The estimated impact of these averted births on numbers of maternal deaths is shown in Table 5. It is estimated that the Indonesia national family planning program averted 592,472 maternal deaths between 1970 and 2017, a $40.4 \%$ reduction. Fifty-seven percent of the maternal deaths averted occurred after the year 2000. As may be observed, this is due to a combination of (1) fewer WRA after 1990 as a result of earlier declines in fertility, (2) fewer women being exposed to the risk of maternal mortality due to not becoming pregnant (i.e. a lower GFR), and (3) a reduced likelihood of dying once pregnant due to a reduction in the number of high-risk births in addition to improvements in maternal health services. Sensitivity analyses indicated that if contraceptive use were to have accounted for $85 \%$ of fertility decline instead of $80 \%$ and the reduction in high-risk births to have accounted for $20 \%$ impact on the MMR instead of $15 \%$ as in the above projection, the number of maternal deaths averted from 1970 to 2017 would have been 663,146 instead of 592,472, a reduction of $43.1 \%$ instead of $40.4 \%$. Less aggressive assumptions (contraceptive use accounting for only $75 \%$ of fertility decline and having only a $10 \%$ impact on the MMR) resulted in an estimate of the number of maternal deaths averted during $1970-2017$ of 523,885 , a reduction of $37.5 \%$.

\section{Potential future contributions}

Given that the CPR in Indonesia reached 63\% in 2017, what is the potential magnitude of further family planning program contributions to reducing maternal deaths? To address this question, we ran two simulations with different assumptions as to future levels of CPR and unmet need for family planning (UNFP) to year 2030. The target CPR in 2030 was set at $70 \%$ in scenario 2 , and $75 \%$ in scenario 3 . UNFP was assumed to decline from $10 \%$ in 2017 to $7 \%$ in 2030 in scenario 2 and $5 \%$ in scenario 3. Annual values of WRA were extracted from Statistics Indonesia population projections to the year 2030 . As the projection period is only 14 years, too short a period time for scenario differences in fertility to affect relative numbers of WRA, the WRA values were the same in the baseline and two alternative scenarios. Baseline annual values of GFR and MMR were calculated assuming no further increases in CPR from 2017 onward.

The projected annual GFR values from 2017 to 2030 under scenarios 2 and 3 were estimated via fitted quadratic regressions of the form:

$$
\mathrm{GFR}_{i}=a+b \mathrm{CPR}_{i}+c \mathrm{CPR}_{i}^{2}+e_{\mathrm{i}}
$$

where:

$$
\begin{aligned}
& \mathrm{GFR}_{i}=\text { estimated GFR for year } \mathrm{i}, \\
& \mathrm{CPR}_{i}=\text { projected CPR for year } \mathrm{i},
\end{aligned}
$$

$a, b$, and $c$ are regression coefficients estimated from the CPR and GFR data from the years 1997-2017

$$
e_{\mathrm{i}}=\text { an error term assumed to uncorrelated with CPR. }
$$

The "diagnostics" for the regressions for the 19972017 period, $\mathrm{GFR}_{i}=580,335+\left(-14,188^{*} \mathrm{CPR}_{\mathrm{i}}\right)+$ $\left(0.097^{*} \mathrm{CPR}_{\mathrm{i}}{ }^{2}\right)$, indicated an $R^{2}$ of 0.995 , and a $X^{2}$ goodness of fit of $0.36(p<.01)$.

The projected annual MMR values from 2017 to 2030 under the two scenarios were estimated via fitted linear regressions of the form:

$$
\mathrm{MMR}_{i}=a+b \mathrm{CPR}_{i}+c \mathrm{UFP}_{i}+e_{i}
$$

where:

$$
\begin{aligned}
& \mathrm{MMR}_{i}=\text { estimated GFR for year } \mathrm{i}, \\
& \mathrm{CPRi}_{i}=\text { projected CPR for year } \mathrm{i}, \\
& \mathrm{UNFP}_{i}=\text { projected UNFP for year } \mathrm{i},
\end{aligned}
$$

$a, b$, and $c$ are regression coefficients estimated from the CPR and UNFP GFR data from the years 1997-2017

Table 4 Estimated number of births averted by the family planning, Indonesia 1970-2017

\begin{tabular}{lllll}
\hline Year & $\begin{array}{l}\text { Births } \\
\text { Baseline }\end{array}$ & $\begin{array}{l}\text { Births } \\
\text { S1 }\end{array}$ & No. births averted & \% Births averted \\
\hline $\mathbf{1 9 7 0 - 1 9 8 4}$ & $74,353,916$ & $85,521,342$ & $11,167,427$ & 13.1 \\
$\mathbf{1 9 8 5 - 1 9 9 9}$ & $72,537,644$ & $117,138,797$ & $44,601,154$ & 38.1 \\
$\mathbf{2 0 0 0 - 2 0 1 4}$ & $70,601,092$ & $147,446,679$ & $76,845,587$ & 52.1 \\
$\mathbf{2 0 1 5 - 2 0 1 7}$ & $15,350,822$ & $33,265,359$ & $17,914,537$ & 53.9 \\
$\mathbf{1 9 7 0 - 2 0 1 7}$ & $232,843,474$ & $383,372,178$ & $150,528,704$ & 39.3 \\
\hline
\end{tabular}

Baseline-observed, smoothed data; S1 = scenario 1 of no family planning program-see text for assumptions 
Table 5 Estimated number of maternal deaths averted by the family planning, 1970-2017

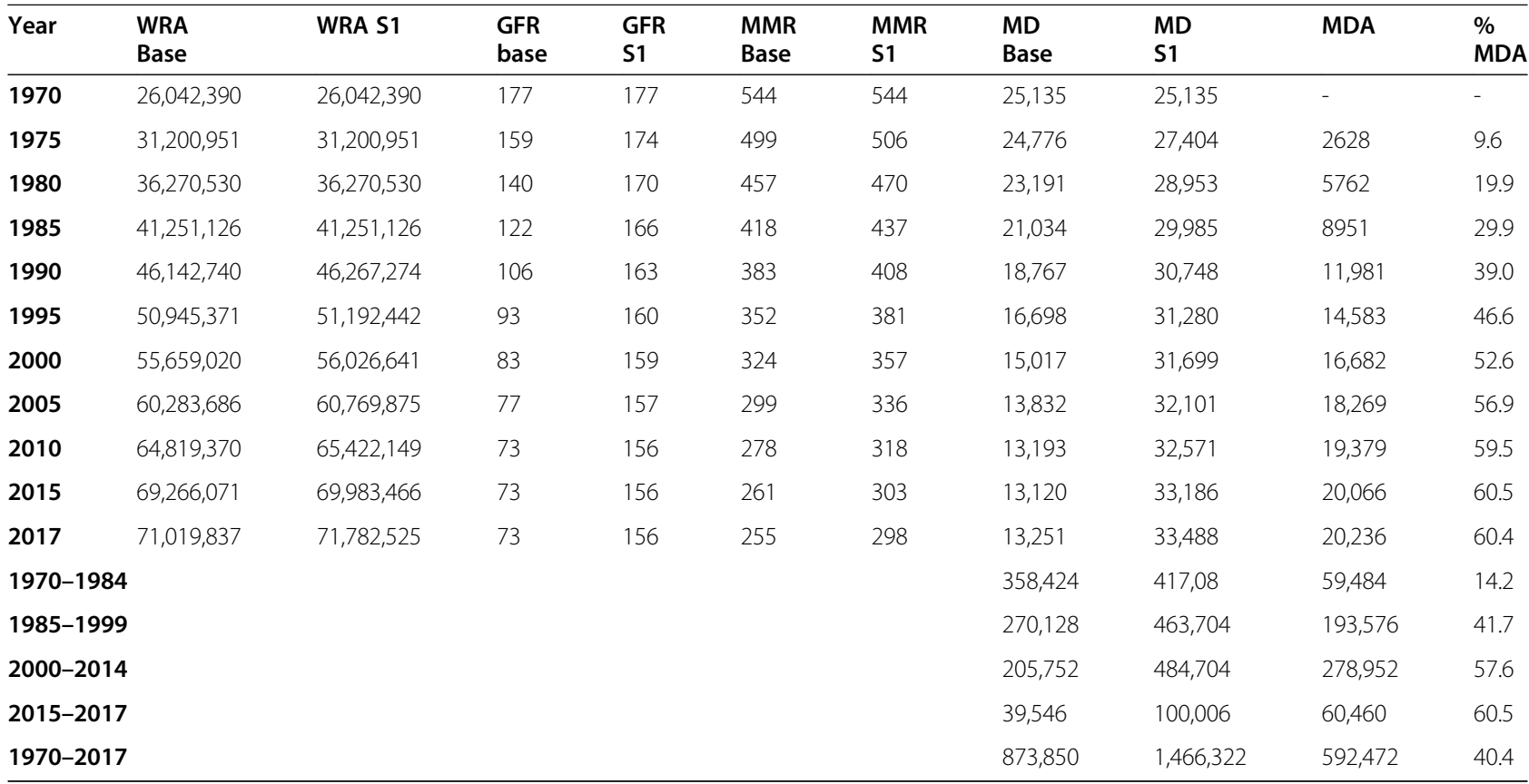

$e_{i}=$ an error term assumed to uncorrelated with CPR and UNFP

The regression "diagnostics" for the 2017-2030 period, $\mathrm{MMR}_{i}=-395,308+\left(31,726 * \mathrm{UNFP}_{\mathrm{i}}\right)+\left(4824 * \mathrm{CPR}_{\mathrm{i}}\right)$, indicated an $R^{2}$ of 0.999 , and a $X^{2}$ goodness of fit of 0.26 $(p>0.01)$.

The resulting projected GFRs and MMRs were then used in decomposition analyses similar to the analyses whose results are presented in Table 5 to estimate the annual number of maternal deaths that would be averted under the two alternative future scenarios against the baseline scenario of no further increase in CPR between 2017 and 2030. As in the above analyses, it was assumed that contraception was responsible for $80 \%$ of the decline in GFR and 15\% of the reduction in the MMR (due to a reduction in the number of unwanted births). The results of the policy simulations are shown in Tables 6 and 7.

If CPR were to increase from $63 \%$ in 2017 to $70 \%$ in 2030 and UNFP to decline from 10 to $7 \%$, it is estimated that 35,897 maternal deaths (19.5\%) would be averted between 2017 and 2030 (Table 6). Sensitivity analyses involving assumptions regarding the responsiveness of fertility to declines in contraceptive use and of the MMR to declines in unmet need for family planning indicate that the impact could be as high as 37,186 maternal deaths averted (a 20\% reduction) in the event of greater responsiveness and as low 34,621 maternal deaths averted (an $18.9 \%$ reduction) in the event of lower responsiveness. The estimates are thus rather robust to varying assumptions as to these underlying parameters, with estimates falling within a relatively narrow range of 34,000 to 37,000 maternal deaths averted.

Further optimizing the family planning program 20172030 by increasing CPR from 63 to $75 \%$ and decreasing UNFP from 10 to $5 \%$ would avert 53,247 maternal deaths (a 28.9\% reduction) between 2017 and 2030 (Table 7). The range of estimates via sensitivity analysis performed as described above lie between 51,971 and 54,536 maternal deaths averted, reductions of $28.4 \%$ and $29.4 \%$, respectively. The estimates again appear to be fairly robust to variations in assumptions concerning key underlying parameters.

\section{Discussion}

The Indonesian national family planning program has over a period spanning just under 50 years (i.e., since 1970) which made a major contribution to the reduction of maternal mortality in the country. Had there not been any increase in the contraceptive prevalence rate from 1970 to 2017, it is estimated that there would have been at least 592,472 and as many as 663,000 additional maternal deaths during this period. This amounts to a 38 $43 \%$ reduction. The maternal mortality rate, or the number of maternal deaths per 1000 women in a given year, fell by nearly $82 \%$ during this period. These estimates are plausible when compared with other global estimates $[1,7,16]$.

In view of the success of national family planning efforts in achieving relatively high levels of contraceptive use, can family planning be expected to continue to make major future contributions to reducing maternal mortality? It is estimated that if the CPR were to be 
Table 6 Estimated number of deaths averted by the family planning, 2017-2030, under scenario 2

\begin{tabular}{lllllllllll}
\hline Year & WRA & WRA & GFR & GFR & MMR & MMR & MD & MD & MDA \\
Base & S2 & Base & S2 & B2 & MDA \\
\hline 2017 & $71,019,837$ & $71,019,837$ & 73 & 73 & 255 & 255 & 13,251 & 13,251 & - \\
2018 & $71,891,381$ & $71,891,381$ & 73 & 70 & 252 & 246 & 13,247 & 12,477 & 770 & 5.8 \\
2019 & $72,759,365$ & $72,759,365$ & 73 & 70 & 249 & 239 & 13,241 & 12,107 & 1133 & 8.6 \\
2020 & $73,623,790$ & $73,623,790$ & 73 & 69 & 247 & 233 & 13,231 & 11,745 & 1487 & 11.2 \\
2021 & $74,484,656$ & $74,484,656$ & 73 & 68 & 244 & 226 & 13,220 & 11,388 & 1832 \\
2022 & $75,341,963$ & $75,341,963$ & 73 & 67 & 241 & 219 & 13,206 & 11,038 & 2168 \\
2023 & $76,195,710$ & $76,195,710$ & 73 & 66 & 239 & 212 & 13,189 & 10,694 & 2496 \\
2024 & $77,045,898$ & $77,045,898$ & 72 & 65 & 236 & 205 & 13,171 & 10,356 & 2815 & 16.4 \\
2025 & $77,892,526$ & $77,892,526$ & 72 & 65 & 234 & 199 & 13,150 & 10,023 & 3127 & 23.4 \\
2026 & $78,735,596$ & $78,735,596$ & 72 & 64 & 231 & 192 & 13,127 & 9,696 & 3431 & 26.1 \\
2027 & $79,575,106$ & $79,575,106$ & 72 & 64 & 229 & 185 & 13,102 & 9,373 & 3729 & 28.5 \\
2028 & $80,411,057$ & $80,411,057$ & 72 & 63 & 226 & 178 & 13,075 & 9,056 & 4020 & 30.7 \\
2029 & $81,243,448$ & $81,243,448$ & 72 & 63 & 224 & 171 & 13,047 & 8,742 & 4305 & 33.0 \\
2030 & $82,072,280$ & $82,072,280$ & 72 & 62 & 221 & 164 & 13,016 & 8,431 & 4584 & 35.2 \\
$2017-2030$ & & & & & & & 184.274 & 148,377 & 35,897 & 19.5 \\
\hline
\end{tabular}

S2: CPR to increase from $63 \%$ in 2017 to $70 \%$ in 2030 , and the unmet need to decrease from $10 \%$ in 2017 to $7 \%$ in 2030

increased to $70 \%$ and unmet need for family planning reduced from 10 to $7 \%$ by 2030 , an additional 35,897 (range 34,621-37,186) maternal deaths could be averted over and above the contributions of improvements in maternal health care in the country, a $19-20 \%$ reduction. If the CPR were instead to be increased to $75 \%$ and UNFP reduced to $5 \%$ by 2030 , the number of additional maternal deaths averted would rise to 53,247 (range 51, $971-54,536)$, a $28-29 \%$ reduction. However, even in the most optimistic scenario, there would still be over 13 ,
000 maternal deaths in the year 2030, and the maternal mortality ratio would still be 125 maternal deaths per 100,000 live births, considerably above the global SDG target of less than 70 maternal deaths per 100,000 live births. Further advances in the provision of high-quality maternal health services by the health system to address risk once women become pregnant will be required in order to reach the SDG target.

Is achieving a CPR of $75 \%$, or even $70 \%$, by 2030 plausible? Such levels of contraceptive prevalence

Table 7 Estimated number of deaths averted, 2017-2030, under scenario 3

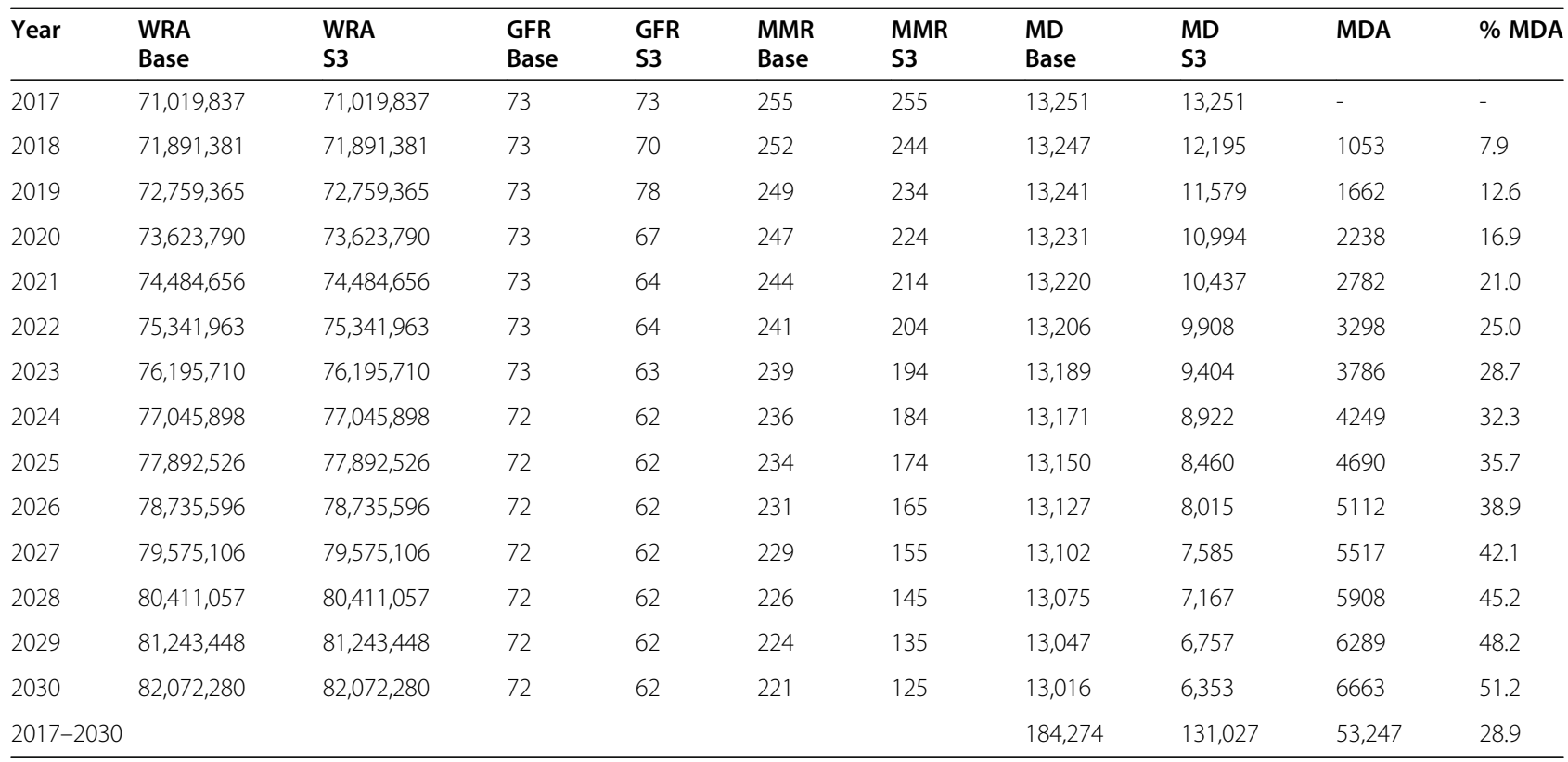


have already been achieved by Association of SouthEast Asian Nations (ASEAN) peer countries Thailand (78.4\%) and Vietnam (76.7\%) [27]. However, the growth in contraceptive use in Indonesia has been weak since the turn of the century, and some observers have pointed to a weakened state of the Indonesian national family planning program due to reduced international support, reduced government commitment, socio-political change, and weak local governance as important constraining factors [11]. Reaching a CPR of $70 \%$ in 2030 would require an annual CPR growth rate of $0.80 \%$ between 2018 and 2030. Reaching a CPR of $75 \%$ by 2030 would require an annual growth rate of $1.32 \%$. By way of reference, the annual growth rate from 2000 to 2017 was $0.44 \%$. Thus, the annual CPR growth rate would have to nearly double to reach the less ambitious target of $70 \%$ CPR in 2030, and triple to reach the more ambitious $75 \%$ target.

The slow growth in contraceptive prevalence in Indonesia in recent years is typical of countries with CPRs approaching or exceeding 60\%. As demonstrated by Alkema et al. [2], the growth in contraceptive use in low- and middle-income countries has followed a logistic curve shaped like the letter "S". This reflects the typical pattern of slow growth in contraceptive use following the introduction of family planning, which gives way to rapid growth once family planning programs have become established and are accepted by governments and sizeable proportions of national populations, followed by a period of slowing growth once the CPR reaches $50-60 \%$. Indonesia is currently and has been since the mid-1990s/early 2000s at a level of contraceptive prevalence where gains have historically come slowly.

In such situations, priority attention needs to be directed to rectifying remaining geographic and socioeconomic inequities in access to accurate information and services, more effectively addressing local barriers and constraints to family planning uptake, providing informed choice across a full range of contraceptive methods, and improving service quality. Satisfying existing total demand for family planning, estimated to be $73.7 \%$ in the 2017 IDHS, would be sufficient to reach the $70 \% 2030$ CPR target, but additional demand for family planning will be needed to reach the $75 \% 2030$ CPR target.

In order to reinvigorate the national family planning program, meaningfully addressing age-, marital status-, and geography-related inequities in access to family planning services would be a logical place to start. At present, access to contraceptives by adolescents and unmarried women is restricted by law. With regard to geography, most Eastern Indonesia provinces and some provinces on the island of Sumatra have levels of demand for family planning and contraceptive use that lag the national norm, some provinces by a considerable margin [21]. Provinces in Eastern Indonesia also have less well-developed health infrastructure. Targeted, integrated family planning-maternal health initiatives that focus on locally-informed solutions to increasing demand for and use of contraception on the one hand and increased investment to address major health system supply-side readiness constraints on the other would seem to have considerable potential to achieve important results at both the local and national level.

Other issues also need to be addressed. The method mix of contraceptive use has shifted from the dominant use of long-acting, reversible contraceptives (IUDs and implants) to a decided dominance of short-term contraceptive methods (i.e., injectable contraceptives and pills) since the early 2000s [12]. Short-term contraceptives, due to higher discontinuation and failure rates, are less effective than long-term contraceptive methods [25] and lead to a larger number of unwanted pregnancies. Although the 2017 IDHS indicated a modest increase in the use of long-acting vs. short-term methods compared to the 2012 IDHS, the market share of traditional methods increased by an even greater amount [20]. Contraceptive discontinuation, that is the proportion of women who discontinue use within the first 12 months after initiation of a method, also remains high, especially for the two most popular contraceptive methods in Indonesiaoral contraceptives (46.1\% market share) and injectables (27.7\%) [20]. Although the 2017 IDHS data indicate that about $75 \%$ of women discontinuing use of oral contraceptives and injectables switch to a new method within six months, this method "churning" is suggestive of insufficient counseling and informed choice at the time of method adoption. Indeed, Indonesia fares rather poorly when it comes to the FP2020 core indicator "Method Information Index," which measures the extent to which women were given specific information when they received family planning services in connection with adoption of the method they are currently using, with a 2017 "score" of only 34 on a $0-100$ scale [24].

These challenges are formidable indeed. Some assistance in reaching the ambitious targets may come from the expansion of the national social health insurance scheme, the Jaminan Kesehatan Nasional (JKN). JKN population coverage reached $80 \%$ by the end of 2019, with the ultimate objective of achieving universal coverage. The JKN is likely to extend the reach of contraceptive services and supplies to areas 
that have limited private sector market penetration and make access to long-acting and permanent contraceptive methods more financially accessible.

\section{Conclusions}

Substantial reductions in maternal mortality between the years 1970 and 2017 can be attributed to the successes of the national family planning program, and there are prospects for further contributions to the year 2030. However, the ability of Indonesia to reach the 2030 SDG maternal mortality target of 70 maternal deaths per 100,000 live births will depend more heavily upon the effectiveness of the health system in addressing health risks to women once they are pregnant.

\section{Annex 1. List of Data Sources}

Indonesian Demographic Health Surveys

Badan Pusat Statistik-Statistics Indonesia (BPS) and ORC Macro. (2003). 'Indonesia Demographic and Health Survey 2002-2003'. Calverton, Maryland, USA: BPS and ORC Macro.

Central Bureau of Statistics (CBS) [Indonesia] and State Ministry of Population/National Family Planning Coordinating Board (NFPCB) and Ministry of Health $(\mathrm{MOH})$ and Macro International Inc. (MI). (1988). 'Indonesia Demographic and Health Survey 1987'. Calverton, Maryland: CBS and MI.

Central Bureau of Statistics (CBS) [Indonesia] and State Ministry of Population/National Family Planning Coordinating Board (NFPCB) and Ministry of Health $(\mathrm{MOH})$ and Macro International Inc. (MI). (1992). 'Indonesia Demographic and Health Survey 1991'. Calverton, Maryland: CBS and MI.

Central Bureau of Statistics (CBS) [Indonesia] and State Ministry of Population/National Family Planning Coordinating Board (NFPCB) and Ministry of Health $(\mathrm{MOH})$ and Macro International Inc. (MI). (1995). 'Indonesia Demographic and Health Survey 1994'. Calverton, Maryland: CBS and MI.

Central Bureau of Statistics (CBS) [Indonesia] and State Ministry of Population/National Family Planning Coordinating Board (NFPCB) and Ministry of Health $(\mathrm{MOH})$ and Macro Intemational Inc. (MI). (1998). 'Indonesia Demographic and Health Survey 1997'. Calverton, Maryland: CBS and MI.

Statistics Indonesia, National Family Planning Coordinating Board, Ministry of Health $(\mathrm{MOH})$, and ORC Macro. (2003). 'Indonesia Demographic and Health Survey 2002-2003'. Calverton, Maryland: CBS and MI.

Statistics Indonesia (Badan Pusat Statistik-BPS) and Macro International. (2008). 'Indonesia Demographic and Health Survey 2007'. Calverton, Maryland, USA: BPS and Macro International.
Statistics Indonesia (Badan Pusat Statistik-BPS), National Population and Family Planning Board (BKKBN), and Kementerian Kesehatan (Kemenkes$\mathrm{MOH}$ ), and ICF International. (2013). 'Indonesia Demographic and Health Survey 2012'. Jakarta, Indonesia: BPS, BKKBN, Kemenkes, and ICF International.

Indonesia Population Censuses and Intercensal Population Surveys

Statistics Indonesia (Badan Pusat Statistik-BPS). 1971. Population of Indonesia: Result of Indonesia Population Census 1971. Jakarta: Statistics Indonesia

Statistics Indonesia (Badan Pusat Statistik-BPS). 1980. Population of Indonesia: Result of Indonesia Population Census 1980. Jakarta: Statistics Indonesia

Statistics Indonesia (Badan Pusat Statistik-BPS). 1985. Population of Indonesia: Result of the 1985 Intercensal Population Survey. Jakarta: Statistics Indonesia

Statistics Indonesia (Badan Pusat Statistik-BPS). 1990. Population of Indonesia: Result of Indonesia Population Census 1990. Jakarta: Statistics Indonesia

Statistics Indonesia (Badan Pusat Statistik-BPS). 1995. Population of Indonesia: Result of the 1995 Intercensal Population Survey. Jakarta: Statistics Indonesia

Statistics Indonesia (Badan Pusat Statistik-BPS). 2000. Population of Indonesia: Result of Indonesia Population Census 2010. Jakarta: Statistics Indonesia

Statistics Indonesia (Badan Pusat Statistik-BPS). 2005. Population of Indonesia: Result of the 2015 Intercensal Population Survey. Jakarta: Statistics Indonesia

Statistics Indonesia (Badan Pusat Statistik-BPS). 2010. Population of Indonesia: Result of Indonesia Population Census 2010. Jakarta: Statistics Indonesia

Statistics Indonesia (Badan Pusat Statistik-BPS). 2015. Population of Indonesia: Result of the 2015 Intercensal Population Survey. Jakarta: Statistics Indonesia

\section{Other Reports/documents}

Hogan M.C., Foreman K.J., Naghavi M., Ahn S.Y., Wang M., Makela S.M., Lopez A.D, Lozano R., and Murray C.J. (2010). 'Maternal mortality for 181 countries, 1980-2008: a systematic analysis of progress towards Millennium Development Goal 5'. Lancet, 375, 9726: 1609 - 1623.

IBFAN (2014). 'Report on the Situation of Infant and Young Child Feeding in Indonesia'. Jakarta: Indonesian Breastfeeding Mothers Association.

Iskandar M.B., Utomo B., Hull T., Dharmaputra N.G., and Azwar Y. (1996). 'Unraveling the mysteries of maternal death in West Java: Reexamining the witnesses. [1st ed.]'. Depok: Center for Health Research, Research Institute, University of Indonesia.

National Research Council. (2013). 'Reducing Maternal and Neonatal Mortality in Indonesia: Saving Lives, 
Saving the Future'. Washington, DC: The National Academies Press

Statistics Indonesia (Badan Pusat Statistik-BPS) and National Family Planning Coordinating Board. (1987). 'Indonesia- National Contraceptive Prevelance Survey 1987'. Calverton, Maryland: CBS and MI.

Statistics Indonesia (Badan Pusat Statistik-BPS), National Family Planning Coordinating Board, Ministry of Health and ICF. (2018). Survei Demografi and Kesehatan Indonesia 2017: Laporan Pendahuluan Indikator Utama. Jakarta: Statistics Indonesia.

Statistics Indonesia (Badan Pusat Statistik-BPS), Bappenas and UNFPA. (2013). 'Indonesia Population Projection 2010-2035'. Jakarta: Statistics Indonesia.

UNDP (2004). 'Human Development Report 2004, Cultural Liberty in Today's Diverse World'. New York: UNDP.

Utomo B. (1976). 'A study of Indonesian Age Data, 1971 and 1976'. Jakarta: Lembaga Demografi FEUI.

\section{Abbreviations}

ASFR: Age-specific fertility rate; CPR: Contraceptive prevalence rate; FP2020: Family Planning 2020; GFR: General fertility rate; IDHS: Indonesia Demographic and Health Survey; JKN: Jaminan Kesehatan Nasional: MD: Maternal deaths; MDA: Maternal deaths averted; MMR: Maternal mortality rate; SDG: Sustainable Development Goals; TFR: Total fertility rate; WRA: Women of reproductive age

\section{Acknowledgements}

The authors acknowledge the UNFPA Indonesia staff, Dr. Melanie Hidayat, Dr. Richard Makalew, and Ms. Elvira Liyanto for their support and encouragement to conduct this study assessing the Indonesia family planning contribution to reducing maternal deaths.

\section{Authors' contributions}

$\mathrm{BU}$ designed and conducted the analysis and co-wrote the manuscript. NA and PS compiled and prepared all the data needed for the analysis. ASR developed the study concept and advised on analysis issues. RM contributed to the analysis and co-wrote the manuscript. IB contributed to preparing the study proposal to UNFPA and reviewed the manuscript. The authors read and approved the final manuscript.

\section{Funding}

This study was financially supported by UNFPA Indonesia.

\section{Availability of data and materials}

The bulk of the data used in the study were produced by the Government of Indonesia, Central Statistics Bureau (Badan Pusat Statistik - BPS), and are in the public domain. Please consult the BPS website for further information on publications and access to data-https://www.bps.go.id/. The Indonesian Demographic and Health Survey (IDHS) reports and data files used in the study are accessible via the DHS/IRC website: www.DHSprogram.com.

\section{Ethics approval and consent to participate}

As the study entailed secondary analysis of existing data containing no personal identifying information, an exemption from ethical review requirements was granted by the University of Indonesia Research Ethics Review Board. Consent to participate was not an issue for the same reason.

\section{Consent for publication}

Not applicable.

\section{Competing interests}

The authors declare that they have no competing interests.

\section{Author details}

Department of Population and Biostatistics, Faculty of Public Health, Universitas Indonesia, Depok, Indonesia. ${ }^{2}$ Center for Health Research, Universitas Indonesia, Depok, Indonesia. ${ }^{3}$ UNFPA Asia and the Pacific Regional Office, Bangkok, Thailand. ${ }^{4}$ UNFPA Indonesia, Jakarta, Indonesia.

${ }^{5}$ Faculty of Public Health, Universitas Indonesia, Depok, Indonesia.

Received: 5 September 2019 Accepted: 28 December 2020

Published online: 11 January 2021

\section{References}

1. Ahmed S, Li Q, Liu L, Tsui AO. Maternal deaths averted by contraceptive use: an analysis of 172 countries. Lancet. 2012;380:111-25. Published Online July 10, 2012. https://doi.org/10.1016/S0140-6736(12)60478-4.

2. Alkema L, Chou D, Hogan D, Zhang S, Moller AB, Gemmill A, et al. Global, regional, and national levels and trends in maternal mortality between 1990 and 2015, with scenario-based projections to 2030: a systematic analysis by the UN Maternal Mortality Estimation Inter-Agency Group. Lancet. 2016; 387(10017):462-74.

3. Alkema L, Kantorova $V$, Menozzi C, Biddlecom A. National, regional and global rates and trends in contraceptive prevalence and unmet need for family planning between 1990 and 2015: a systematic and comprehensive analysis. Lancet. 2013;381(9878):1642-52.

4. Bongaarts J. A framework for analyzing the proximate determinants of fertility. Popul Dev Rev. 1978;4(1):105-32.

5. Bongaarts J. Trends in unwanted childbearing in the developing world. Stud Fam Plan. 1997;28(4):267-77.

6. Bongaarts J. Modeling the fertility impact of the proximate determinants: time for a tune-up. Demogr Res. 2015;33(19):535-60.

7. Cleland J, Conde-Agudelo A, Peterson H, Ross J, Tsui A. Contraception and health. Lancet. 2012;380(9837):149-56. https://doi.org/10.1016/S01406736(12)60609-6.

8. Fortney JA. The importance of family planning in reducing maternal mortality. Stud Fam Plan. 1987;18(2):109-14.

9. Gillespie D, Ahmed S, Tsui A, Radloff S. Unwanted fertility among the poor: an inequity? Bull World Health Organ. 2007;85:100-7.

10. Hasbullah M.S., Surbakti I.M., and Handiyatmo D. (2016). Kematian maternal di Indonesia hasil Supas 2015. Forum Masyarakat Statistik. Statistical and Policy Brief. Edisi 8.

11. Hayes AC. The UNFPA-BKKBN partnership regarding family planning under the $8^{\text {th }}$ Country Programme. UNFPA Indonesia, Jakarta: Strategy Paper; 2012.

12. Hidayat M. Analisis ketidak-sesuaian metode penggunaan kontrasepsi pada perempuan peserta Keluarga Berencana - Fenomena Unmet Need Tipe 2. Disertasi: Program Studi IImu Kesehatan Masyarakat, Fakultas Kesehatan Masyarakat Universitas Indonesia, Depok, Jawa Barat; 2015.

13. Marston C, Cleland J. The effects of contraception on obstetric outcomes. Department of Reproductive Health. Geneva: World Health Organization; 2004.

14. Mbizvo MT, Burke A. Family planning global conference series. Editorial. BMC Reprod Health. 2016;13:9.

15. Robey B, Rutstein SO, Morris L. The fertility decline in developing countries. Sci Am. 1993;269(6):60-7.

16. Ross JA, Blanc AK. Why aren't there more maternal deaths? A Decomposition Analysis. Matern Child Health J. 2012;16:456-63. https://doi. org/10.1007/s10995-011-0777-x Published online: 24 March 2011.

17. Soemantri S. (2014). Telaah perkiraan AKI (MM Ratio) untuk Indonesia. Forum Masyarakat Statistik. Statistical and Policy Brief. Edisi 4.

18. Statistics Indonesia (Badan Pusat Statistik-BPS). Proyeksi Penduduk Indonesia 2010-2035. Jakarta: Badan Pusat Statistik; 2013.

19. Statistics Indonesia (Badan Pusat Statistik-BPS). Profil Penduduk Indonesia Hasil SUPAS. Jakarta: Badan Pusat Stastistik; 2015

20. Statistics Indonesia (Badan Pusat Statistik-BPS), National Family Planning Coordinating Board, Ministry of Health and ICF. Survei Demografi and Kesehatan Indonesia 2017: Laporan Pendahuluan Indikator Utama. Jakarta: Statistics Indonesia; 2018.

21. Statistics Indonesia (Badan Pusat Statistik-BPS), National Population and Family Planning Board (BKKBN), Kementerian Kesehatan (Kemenkes-MOH), ICF International. Indonesia Demographic and Health Survey 2017. Jakarta: BPS, BKKBN, Kemenkes, and ICF International; 2017.

22. Statistics Indonesia (Badan Pusat Statistik-BPS), National Population and Family Planning Board (BKKBN), and Kementerian Kesehatan 
(Kemenkes-MOH), and ICF International, (2013), Indonesia Demographic and Health Survey 2012, Jakarta.

23. Stover J, Ross J. How increased contraceptive use has reduced maternal mortality. Matern Child Health J. 2010;14:687-95.

24. Track20. FP2020 Core Indicators. CT, USA: Glastonbury; 2019. www.track20. org/StatTrack.

25. Trussell J. Understanding contraceptive failure. Best Pract Res Clin Obstet Gynaecol. 2009;23(2):199-209 https://doi.org/10.1016/j.bpobgyn.2008.11.008,

26. Tsui AO, McDonald-Mosley R, Burke AE. Family planning and the burden of unintended pregnancies. Epidemiol Rev. 2010;32(1):152-74.

27. United Nations Population Division. World Family Planning 2017. New York: UN, Department of Economic and Social Affairs; 2017.

28. WHO. Mother-baby package: implementing safe motherhood in countries. Geneva: World Health Organization; 1996. http://whqlibdoc.who.int/hq/1 994/WHO_FHE_MSM_94.11_Rev.1.pdf Accessed 24 Mar 2019

29. WHO. Strategies towards ending preventable maternal mortality (EPMM). Geneva: World Health Organization; 2015.

30. WHO, UNICEF, UNFPA, World Bank Group, and the United Nations Population Division. Trends in maternal mortality: 1990-2017. Geneva: World Health Organization; 2017.

\section{Publisher's Note}

Springer Nature remains neutral with regard to jurisdictional claims in published maps and institutional affiliations.

Ready to submit your research? Choose BMC and benefit from:

- fast, convenient online submission

- thorough peer review by experienced researchers in your field

- rapid publication on acceptance

- support for research data, including large and complex data types

- gold Open Access which fosters wider collaboration and increased citations

- maximum visibility for your research: over $100 \mathrm{M}$ website views per year

At BMC, research is always in progress.

Learn more biomedcentral.com/submissions 